\title{
Infection Status with Clonorchis sinensis Metacercariae in Fish from Tamjin-gang (River) in Jeollanam-do, Republic of Korea
}

\author{
Ki-Bok Yoon', Hyun-Cheol Lim¹, Doo Young Jeon'1, Sook Park', Shin-Hyeong Cho², Jung-Won Ju², \\ Sung-Shik Shin ${ }^{3}$, Byoung-Kuk Na ${ }^{4}$, Woon-Mok Sohn ${ }^{4, *}$ \\ 'Division of Microbiology, Jeollanam-do Institute of Health and Environment, Muan 58568, Korea; '2Division of Vectors and Parasitic Diseases, \\ Centers for Disease Control and Prevention, Osong 28159, Korea; ${ }^{3}$ Department of Parasitology, College of Veterinary Medicine, Chonnam National \\ University, Gwangju 61186, Korea; ${ }^{4}$ Department of Parasitology and Tropical Medicine, and Institute of Health Sciences, Gyeongsang National \\ University College of Medicine, Jinju 52727, Korea
}

\begin{abstract}
The present study was performed to investigate the infection status with Clonorchis sinensis metacercariae (CsMc) in fishes from 2 sites, the middle and lower reaches, of Tamjin-gang (River) in Jeollanam-do, the Republic of Korea. Total 1,132 fishes in 22 species were collected from the middle reaches in Jangheung-gun for 4 years (2014-2017) and 517 fishes in 17 species were also collected from the lower reaches in Gangjin-gun in 2014 and 2017. They were all individually examined with the artificial digestion method in our laboratory. CsMc were detected in 322 (28.5\%) out of 1,132 fishes from Jangheung-gun, and in 161 (31.1\%) out of 517 fishes from Gangjin-gun, and their densities were 51 and 57 per fish infected each. In the fish species with CsMc, positive rates were $61.5 \%$ in Jangheung-gun and $62.7 \%$ in Gangjin-gun. A total of 222 Pungtungia herzi were examined and they were all infected with CsMc. The average intensity was 103 CsMc in the index fish, $P$. herzi (95 in Jangheung-gun and 121 in Gangjin-gun). In P. herzi bimonthly examined in 2017, the intensity was commonly most higher in March in 2 surveyed sites, however the significant seasonal endemicity was not showed. Conclusively, it was confirmed that CsMc is more or less prevalent in fishes from Tamjin-gang and their endemicity is higher in fish from the lower reaches in Gangjin-gun than the middle reaches in Jangheung-gun in Jeollanam-do, Korea.
\end{abstract}

Key words: Clonorchis sinensis, metacercaria, freshwater fish, index fish, Pungtungia herzi, Tamjin-gang

\section{INTRODUCTION}

In the nationwide survey on the helminthic infection in the Republic of Korea (Korea), the prevalence of clonorchiasis, Clonorchis sinensis infection, was $1.86 \%, 932,540$ residents with this endemic disease estimated. Nowadays, it is the highest value among the prevalences of parasitic diseases in Korea [1]. The prevalence of this endemic disease has maintained at relatively high levels in residents of riverside areas in Korea [26]. Especially, Cho et al. [5] reported the egg positive rates of $C$. sinensis in residents living in the 4 river basins, Nakdong-gang (gang means River), Seomjin-gang, Yeongsan-gang and Geum-

\footnotetext{
- Received 19 February 2018, revised 20 March 2018, accepted 10 April 2018.

*Corresponding author (wmsohn@gnu.ac.kr)

(C) 2018, Korean Society for Parasitology and Tropical Medicine

This is an Open Access article distributed under the terms of the Creative Commons

Attribution Non-Commercial License (http://creativecommons.org/licenses/by-nc/4.0) which permits unrestricted non-commercial use, distribution, and reproduction in any

medium, provided the original work is properly cited.
}

gang, located in southern part of Korea. Recently, Jeong et al. [6] reported the prevalences of clonorchiasis in the adjacent residents of 5 major rivers, i.e., Nakdong-gang, Seomjin-gang, Geum-gang, Yeongsan-gang and Han-gang. However, the endemicity of this trematode infections is rarely reported in the riverside residents of Tamjin-gang except for the Seo et al. [2] performed in 1981.

Many Korean parasitologists examined freshwater fishes, the infection source of clonorchiasis, from various endemic areas to estimate the endemicities of liver fluke infections [7-16]. Especially, in 2008, Kim et al. [10] widely surveyed freshwater fishes from 34 localities to know the infection status with $\mathrm{Clo}$ norchis sinensis metacercariae (CsMc) in Korea. Cho et al. [12] investigated the infection status of CsMc in freshwater fish from 3 wide regions, which tentatively divided by the latitudinal levels of Korean peninsula in 2011. Cho et al. [13] also surveyed on the prevalence of zoonotic trematode metacercariae in freshwater fish from Gangwon-do (do=Province), Korea. 
Sohn et al. [14] investigated the infection status of digenetic trematode metacercariae including $C$. sinensis in freshwater fish from the water systems of Hantan-gang and Imjin-gang located in relatively northern regions of Korea. Recently, Sohn et al. [15] surveyed the prevalence of CsMc in freshwater fishes from the water systems of Seomjin-gang. Sohn et al. [16] also reported the infection tendency of CsMc by the subfamily groups in Cyprinidae fish hosts from a highly endemic site, Wicheon (a branch of Nakdong-gang), in Gunwi-gun, Gyeongsangbuk-do, Korea.

Tamjin-gang is one of the 3 major rivers in Jeollanam-do together with Seomjin-gang and Yeongsan-gang. It rises from a mountinous area between Yuchi-myeon (myeon = township) in Jangheung-gun (gun=county) and Geumjeong-myeon in Yeongam-gun, flows via Jangheung-gun and Gangjin-gun and flows into the South Sea in the Gangin Bay, Jeollanam-do, Korea [17]. Its riverside areas have been known as the endemic area of intestinal fluke, Metagonimus yokogawai and heterophyid flukes [2,18-22]. However, the infection status with CsMc in fish from this river has not been widely and systematically examined yet. Therefore, we performed the present study to investigate the infection status with CsMc in fish from 2 local sites of Tamjin-gang in Korea.

\section{MATERIALS AND METHODS}

\section{Fish collection}

Total 1,132 fishes in 22 species were collected in the middle reaches of Tamjin-gang (River) in Jangheung-gun (Latitude: 34.4257; Longitude: 126.5432), Jeollanam-do, Korea for 4 years (2014-2017). Total 517 fishes in 17 species were also collected in the lower reaches of Tamjin-gang in Gangjin-gun (Latitude: 34.3805; Longitude: 126.4851), Jeollanam-do in 2104 and 2017.

\section{Fishes collected from the middle reaches of Tamjin-gang} in Jangheung-gun

Total 167 fishes in 13 species were examined in 2014. Fish species (no. of fish) examined were Zacco temminckii (30), Carassius auratus (25), Zacco platypus (20), Acheilognathus yamatsutae (11), Odontobutis platycephala (6), Micropterus salmoides (5), Acanthorhodeus gracilis (1) including 6 ones with CsMc in Table 1. Total 243 fishes in 15 species were examined in 2015. Fish species (no. of fish) examined were Z. temminckii (32), C. auratus (30), Z. platypus (27), Coreoperca kawamebari (27),
Table 1. Infection status of Clonorchis sinensis metacercariae in fishes from the middle reaches of Tamjingang (River) in Jangheung-gun, Jeollanam-do

\begin{tabular}{|c|c|c|c|c|}
\hline \multirow[t]{2}{*}{ Year and fish sp. } & \multirow{2}{*}{$\begin{array}{c}\text { No. of } \\
\text { fish } \\
\text { examined }\end{array}$} & \multirow{2}{*}{$\begin{array}{l}\text { No. (\%) of } \\
\text { fish } \\
\text { infected }\end{array}$} & \multicolumn{2}{|c|}{$\begin{array}{c}\text { No. of } \\
\text { CsMc } \\
\text { detected }\end{array}$} \\
\hline & & & Range & Average \\
\hline \multicolumn{5}{|l|}{2014} \\
\hline Pseudogobio esocinus & 25 & 2 (8.0) & $1-2$ & 1.5 \\
\hline Hemibarbus longirostris & 20 & 19 (95.0) & $1-20$ & 6.8 \\
\hline Pungtungia herzi & 14 & $14(100)$ & $15-500$ & 185.6 \\
\hline Hemiculter eigenmanni & 6 & $4(66.7)$ & $1-27$ & 8.0 \\
\hline Coreoperca herzi & 3 & $1(33.3)$ & - & 1.0 \\
\hline Sarcocheilichthys nigripinnis & 1 & $1(100)$ & - & 54.0 \\
\hline Subtotal & 69 & $41(59.4)$ & $1-500$ & 68.7 \\
\hline \multicolumn{5}{|l|}{2015} \\
\hline Pungtungia herzi & 35 & $35(100)$ & $2-325$ & 65.7 \\
\hline Pseudogobio esocinus & 20 & $2(10.0)$ & - & 1.0 \\
\hline Sarcocheilichthys variegatus & 14 & $14(100)$ & $1-66$ & 17.2 \\
\hline Odontobutis platycephala & 12 & $1(8.3)$ & - & 1.0 \\
\hline Acheilognathus yamatsutae & 9 & $2(22.2)$ & $1-4$ & 2.5 \\
\hline Acheilognathus rhombeus & 5 & $4(80.0)$ & $2-29$ & 9.0 \\
\hline Hemibarbus longirostris & 4 & $2(50.0)$ & $1-5$ & 3.0 \\
\hline Squalidus gracilis majimae & 3 & $2(66.7)$ & $3-85$ & 44.0 \\
\hline Sarcocheilichthys nigripinnis & 3 & $2(66.7)$ & $1-16$ & 8.5 \\
\hline Subtotal & 105 & $64(61.0)$ & $1-325$ & 42.1 \\
\hline \multicolumn{5}{|l|}{2016} \\
\hline Pungtungia herzi & 36 & $36(100)$ & $2-950$ & 181.3 \\
\hline Zacco platypus & 30 & $2(6.7)$ & - & 1.0 \\
\hline Pseudogobio esocinus & 29 & $1(3.5)$ & - & 1.0 \\
\hline Acheilognathus lanceolatus & 27 & $2(7.4)$ & - & 1.0 \\
\hline Hemibarbus longirostris & 21 & $8(38.1)$ & $1-29$ & 7.6 \\
\hline Sarcocheilichthys variegatus & 17 & 15 (88.2) & $1-46$ & 12.1 \\
\hline Sarcocheilichthys nigripinnis & 15 & $15(100)$ & $1-116$ & 32.2 \\
\hline Acanthorhodeus gracilis & 9 & $9(100)$ & $1-28$ & 8.2 \\
\hline Subtotal & 184 & $88(47.8)$ & $1-950$ & 82.3 \\
\hline \multicolumn{5}{|l|}{2017} \\
\hline Pungtungia herzi & 67 & $67(100)$ & $1-240$ & 45.0 \\
\hline Hemibarbus longirostris & 32 & $17(53.1)$ & $1-12$ & 3.6 \\
\hline Acheilognathus lanceolatus & 25 & $9(36.0)$ & $1-4$ & 1.3 \\
\hline Sarcocheilichthys variegatus & 23 & $22(95.7)$ & $1-133$ & 23.7 \\
\hline Sarcocheilichthys nigripinis & 10 & $8(80.0)$ & $1-5$ & 3.0 \\
\hline Acheilognathus rhombeus & 5 & $2(40.0)$ & - & 2.0 \\
\hline Acheilognathus koreensis & 3 & $3(100)$ & $1-2$ & 1.3 \\
\hline Acanthorhodeus gracilis & 1 & $1(100)$ & - & 1.0 \\
\hline Subtotal & 166 & $129(77.7)$ & $1-240$ & 28.3 \\
\hline Total & 524 & $322(61.5)$ & $1-950$ & 50.9 \\
\hline
\end{tabular}

Plecoglossus altivelis (18), Acheilognathus koreensis (4) including 9 ones with CsMc in Table 1.

Total 302 fishes in 16 species were examined in 2016. Fish species (no. of fish) examined were Z. temminckii (28), C. kawamebari (24), P. altivelis (22), C. auratus (20), O. platycephala (12), Siniperca scherzeri (6), C. herzi (3) and M. salmoides (3) including 8 ones with CsMc in Table 1. Total 420 fishes in 18 species were examined in 2017. Fish species (no. of fish) examined were Z. temminckii (62), Z. platypus (61), C. auratus (41), 
Table 2. Infection status of Clonorchis sinensis metacercariae in Pungtungia herzi from the middle reaches of Tamjingang (River) in Jangheung-gun, Jeollanam-do

\begin{tabular}{|c|c|c|c|c|}
\hline \multirow[t]{2}{*}{ Year } & \multirow{2}{*}{$\begin{array}{c}\text { No. of } \\
\text { fish } \\
\text { examined }\end{array}$} & \multirow{2}{*}{$\begin{array}{l}\text { No. (\%) of } \\
\text { fish } \\
\text { infected }\end{array}$} & \multicolumn{2}{|c|}{$\begin{array}{c}\text { No. of CsMc } \\
\text { detected }\end{array}$} \\
\hline & & & Range & Average \\
\hline 2014 & 14 & 14 (100) & $15-500$ & 185.6 \\
\hline 2015 & 35 & 35 (100) & 2-325 & 65.7 \\
\hline 2016 & 36 & 36 (100) & $2-950$ & 181.3 \\
\hline 2017 & 67 & 67 (100) & $1-240$ & 45.0 \\
\hline March & 15 & 15 (100) & $9-240$ & 113.4 \\
\hline May & 20 & 20 (100) & $4-75$ & 20.7 \\
\hline July & 20 & 20 (100) & $1-90$ & 30.2 \\
\hline October & 12 & 12 (100) & $4-100$ & 24.9 \\
\hline Total & 152 & $152(100)$ & $1-950$ & 95.0 \\
\hline
\end{tabular}

C. kawamebari (33), O. platycephala (18), P. altivelis (12), P. esocinus (12), C. herzi (10), A. yamatsutae (3) and Cyprinus carpio (2), including 8 ones with CsMc in Table 1.

\section{Fishes collected from the lower reaches of Tamjin-gang in Gangjin-gun}

Total 110 fish in 12 species were examined in 2014. Fish species (no. of fish) examined were $Z$. platypus (20), C. auratus (19), Z. temminckii (5), Lateolabrax japonicus (2), O. platycephala (1) and Mugil cephalus (1) including 6 ones with CsMc in Table 3. Total 407 fishes in 14 species were examined in 2017. Fish species (no. of fish) examined were Z. platypus (55), C. auratus (43), P. altivelis (40), C. kawamebari (25), O. platycephala (25), Z. temminckii (21) and C. herzi (3), including 7 ones with CsMc in Table 3.

\section{Examination methods}

All collected fishes with ice were transferred to the laboratory of the Department of Parasitology and Tropical Medicine, Gyeongsang National University College of Medicine, Jinju, Korea. After the identification of fish species, they were individually ground with a mortar or grinder. Each ground fish meat was mixed with artificial gastric juice and the mixture was incubated at $36^{\circ} \mathrm{C}$ for $2 \mathrm{hr}$. The digested material was filtered with $1 \times 1 \mathrm{~mm}$ of mesh, and washed with $0.85 \%$ saline until the supernatant is clear. The sediment was carefully examined under a stereomicroscope. CsMc were separately collected by the general feature [11], and they were counted to get hold of infection rates (\%) and densities (No. of CsMc per fish infected) by fish species.
Table 3. Infection status of Clonorchis sinensis metacercariae in fishes from the lower reaches of Tamjingang (River) in Gangjingun, Jeollanam-do

\begin{tabular}{|c|c|c|c|c|}
\hline \multirow[t]{2}{*}{ Year and fish sp. } & \multirow{2}{*}{$\begin{array}{l}\text { No. of } \\
\text { fish } \\
\text { examined }\end{array}$} & \multirow{2}{*}{$\begin{array}{l}\text { No. (\%) of } \\
\text { fish } \\
\text { infected }\end{array}$} & \multicolumn{2}{|c|}{$\begin{array}{l}\text { No. of } \\
\text { CsMc } \\
\text { detected }\end{array}$} \\
\hline & & & Range & Average \\
\hline \multicolumn{5}{|l|}{2014} \\
\hline Acanthorhodeus macropterus & 28 & 8 (28.6) & $1-4$ & 1.6 \\
\hline Pseudogobio esocinus & 20 & $4(20.0)$ & $1-2$ & 1.3 \\
\hline Acheilognathus lanceolatus & 8 & $3(37.5)$ & $1-2$ & 1.7 \\
\hline Pungtungia herzi & 3 & $3(100)$ & $146-427$ & 242.0 \\
\hline Sarcocheilichthys variegatus & 2 & $2(100)$ & 28-34 & 31.0 \\
\hline Acheilognathus rhombeus & 1 & $1(100)$ & - & 12.0 \\
\hline Subtotal & 62 & $21(33.9)$ & $1-427$ & 39.2 \\
\hline \multicolumn{5}{|l|}{2017} \\
\hline Pungtungia herzi & 67 & $67(100)$ & $7-745$ & 115.4 \\
\hline Sarcocheilichthys nigripinis & 33 & $33(100)$ & $1-57$ & 12.4 \\
\hline Pseudogobio esocinus & 31 & 1 (3.2) & - & 1.0 \\
\hline Hemibarbus longirostris & 24 & $12(50.0)$ & $1-6$ & 2.6 \\
\hline Sarcocheilichthys variegatus & 18 & $18(100)$ & $1-33$ & 11.1 \\
\hline Acheilognathus lanceolatus & 14 & $3(21.4)$ & - & 1.0 \\
\hline Acheilognathus rhombeus & 8 & $6(75.0)$ & $1-6$ & 2.7 \\
\hline Subtotal & 195 & $140(71.8)$ & $1-745$ & 59.9 \\
\hline Total & 257 & $161(62.7)$ & $1-745$ & 57.2 \\
\hline
\end{tabular}

\section{RESULTS}

\section{Infection status of fish with CsMc in middle reaches of Tamjin-gang}

The metacercariae of C. sinensis (CsMc) were detected in 322 (61.5\%) out of 524 fishes in 16 species from the middle reaches of Tamjin-gang in Jangheung-gun, Jeollanam-do, and their average density was 51 per fish infected. In the positive fish species with CsMc, prevalences were 59.4\%, 61.0\%, 47.8\%, and $77.7 \%$ from 2014 to 2017 and their densities were 69, 42, 82 and 28 per fish infected respectively. The infection status with CsMc by the fish species and surveyed years was detailedly shown in Table 1. All 152 striped shinner, P. herzi, examined were infected with CsMc, of which intensities were 186, 66, 181, and 45 in average from 2014 to 2017. In case of this fish species examined in 2017, intensities with CsMc were 113 in March, 21 in May, 30 in July and 25 in October respectively (Table 2).

\section{Infection status of fish with CsMc in lower reaches of Tamjin-gang}

The CsMc were detected in 161 (62.7\%) out of 257 fishes in 8 species from the lower reaches of Tamjin-gang in Gangingun, Jeollanam-do, and their average density was 57 per fish infected. In the positive fish species, prevalences were 33.9\% 
in 2014 and $71.8 \%$ in 2017 and their densities were 39 and 60 CsMc per fish infected. The infection status with CsMc by the fish species and surveyed years was detailedly revealed in Table 3. All 70 striped shinner, P. herzi, examined were infected with CsMc, of which intensities were 242 and 115 in average in 2014 and 2017. In case of this fish species examined in 2017, intensities with CsMc were 195 in March, 64 in May, 59 in July and 136 in October respectively (Table 4).

\section{Comparison of the infection status of fish with CsMc in 2 surveyed sites of Tamjin-gang}

Total 1,649 fishes were examined in this study. Among them, 1,132 (68.7\%) were caught from the middle reaches of Tamjin-gang in Jangheung-gun and remain 517 (31.4\%) were from the lower reaches in Gangin-gun, Jeollanam-do. The overall positive rate with CsMc was $29.3 \%$ in 1,649 fishes from Tamjin-gang. That was $28.5 \%$ in 1,132 fishes from Jangheung-gun and was $31.1 \%$ in 517 fishes from Gangjin-gun. A total of $222 P$. herzi were examined and they were all infected with CsMc. The average density was $103 \mathrm{CsMc}$ in the index fish, P. herzi (95 in Jangheung-gun and 121 in Gangiin-gun) (Table 5).

Table 4. Infection status of Clonorchis sinensis metacercariae in an index fish, Pungtungia herzi, from the lower reaches of Tamjingang (River) in Gangjin-gun, Jeollanam-do

\begin{tabular}{|c|c|c|c|c|}
\hline \multirow[t]{2}{*}{ Year } & \multirow{2}{*}{$\begin{array}{l}\text { No. of } \\
\text { fish } \\
\text { examined }\end{array}$} & \multirow{2}{*}{$\begin{array}{l}\text { No. (\%) of } \\
\text { fish } \\
\text { infected }\end{array}$} & \multicolumn{2}{|c|}{$\begin{array}{l}\text { No. of CsMc } \\
\text { detected }\end{array}$} \\
\hline & & & Range & Average \\
\hline 2014 & 3 & $3(100)$ & $146-427$ & 242.0 \\
\hline 2017 & 67 & 67 (100) & 7-745 & 115.4 \\
\hline March & 20 & $20(100)$ & $7-745$ & 194.8 \\
\hline May & 15 & $15(100)$ & $7-267$ & 63.6 \\
\hline July & 19 & $19(100)$ & $12-217$ & 58.6 \\
\hline October & 13 & $13(100)$ & $28-265$ & 136.2 \\
\hline Total & 70 & $70(100)$ & $7-745$ & 120.9 \\
\hline
\end{tabular}

\section{DISCUSSION}

By the present study, it was confirmed that CsMc are more or less prevalent in fish from Tamjin-gang. Total positive rate, 29.3\%, and average metacercarial density, 53 per fish infected, were not so high (Table 5). However, the prevalence (100\%) and metacercarial density (103) in the index fish, P. herzi, were shown the relatively higher level. In the positive fish species group, the endemicity of CsMc was slightly higher in fish from the lower reaches in Gangiin-gun (prevalence: 62.7\%; density: 57) than in fish from the middle reaches in Jangheung-gun (61.5\%; 51). In P. herzi, the metacercarial density was higher in the lower reaches (121) than in the middle reaches (95). These findings suggested that the endemicity with CsMc is more or less higher in fish from the lower reaches in Gangjin-gun than in fish from the middle reaches in Jangheung-gun, Jeollanamdo, Korea.

Cho et al. [12] examined fishes from 2 sites, Gangjin-gun (58 fish in 11 spp.) and Jangheung-gun (52 fish in 9 spp.), of Tamjin-gang in 2005. They detected 206 CsMc per infected fish in 39 (76.5\%) out of 51 fishes ( 9 spp.) from Gangin-gun, but they found no CsMc in 52 fishes from Jangheung-gun. From these findings, we can speculate that the endemicity of CsMc has been highly maintained in fish from Gangin-gun, however, no CsMc in fish from Jangheung-gun unlike in this study is questionable. Two fish species, $P$. herzi and S. variegatus wakive, were showed to be the highly susceptible fish hosts of $C$. sinensis in Cho et al. [12]. Their susceptibility index of CsMc, 420 in P. herzi and 356 in S. variegatus wakiye, were very high, when we compared with those of present study, 103 in $P$. herzi. On the other hand, Sohn et al. [16] reported that the susceptibility index of CsMc is 1,310 in 323 gobioninid fishes, i.e., 169 P. herzi, 117 Squalidus spp., 25 S. variegatus wakive, and 12 Pseudorasbora parva, from Wicheon in Gunwi-gun, Gyeongsangbuk-do. Kim et al. [10] reported 81 CsMc in average densi-

Table 5. Comparison of the infection status ${ }^{\mathrm{a}}$ with C. sinensis metacercariae in fish from 2 regions of Tamjin-gang (River)

\begin{tabular}{lcrr}
\hline \multirow{2}{*}{ Items } & \multicolumn{3}{c}{ Infection status of C. sinensis metacercariae in fish from } \\
\cline { 2 - 4 } & Jangheung-gun & Gangjin-gun & Total \\
\hline No. of fish examined & $1,332(68.7)$ & $517(31.4)$ & $1,649(100)$ \\
Overall positive rate $(\%)$ & $322 / 1,132(28.5)$ & $161 / 517(31.1)$ & $483 / 1,649(29.3)$ \\
Total metacercarial density & 50.9 & 57.2 & 53.0 \\
No. $(\%)^{b}$ of $P$. herzi examined & $152(13.4)$ & $70(13.5)$ & $222(13.5)$ \\
Metacercarial density in $P$. herzi & 95 & 120.9 & 103.2
\end{tabular}

aPositive rate: No. of fish infected/No. of fish examined ×100; metacercarial density: mean no. of CsMc per fish infected.

${ }^{b}$ No. of $P$. herzi/Total No. of fish examined $\times 100$. 
ty in 10 P. herzi, from Yangcheon in Sancheong-gun, Gyeongsangnam-do.

In the metacercarial surveys for the epidemiology of zoonotic trematode infections, the sampling of fish is one of the important factors to obtain the more precise information. Total 1,649 fishes were collected from 2 sites (1,132 from the middle reaches in Jangheung-gun and 517 from the lower reaches in Gangiin-gun, Jeollanam-do) of Tamjin-gang in this study. In the middle reaches, total 1,132 fishes in 22 species were examined for 4 years (2014-2017) and a total of 517 fishes in 17 species from the lower reaches were examined in 2014 and 2017. The difference of fish number examined in 2 surveyed areas is depends upon the number of examined years. The striped shinner, $P$. herzi (222: 13.5\%), was the most dominant fish species, and followed by pale chub, Z. platypus (213: 12.9\%), dark chub, Z. temminckii (178: 10.8\%), crusian carp, C. auratus (178: 10.8\%), and goby minnow, P. esocinus (137: $8.3 \%$ ) among the fish species examined in this study. The numbers of striped shinner examined in each 2 reaches were 152 (middle: 13.4\%) and 70 (lower: 13.5\%). Those of pale chub were 138 (12.2\%) and 75 (14.5\%), and of crusian carp were $116(10.3 \%)$ and 62 (12.0\%). According to the above findings, major 4 fish species were collected in similar proportions in 2 surveyed areas. However, the dark chub, Z. temminckii, was collected more in the middle (152: 13.4\%) than in the lower reaches (26: 5.0\%).

Total 51 fish species (in 36 genera 9 families) have been reported as the second intermediate hosts of $C$. sinensis in Korea [7-16]. In the present study, CsMc were detected in 16 fish species, i.e., Acanthorhodeus gracilis, A. macropterus, Acheilognathus lanceolatus, A. koreensis, A. rhombeus, A. yamatsutae, Coreoperca herzi, Hemibarbus longirostris, Hemiculter eigenmanni, Odontobutis platycephala, Pseudogobio esocinus, Pungtungia herzi, Sarcocheilichthys nigripinnis morii, S. variegatus wakive, Squalidus gracilis majimae, and Zacco platypus. They all had been listed as the second intermediate hosts of $C$. sinensis in Korea [9-16].

According to the recent studies, CsMc were found in fishes from the water system of Imjingang and Hantangang located in the northern part of Korea, although their prevalences and densities were very low [14]. Whereas CsMc were not detected at all in fishes from the water systems of Hangang in Gangwon-do [13]. In fishes from Geumgang, the prevalence and density of CsMc were also revealed in a low level [12]. They were showed in the moderate level in fishes from Yeongsangang and Seomjingang in Jeollanam-do $[12,15]$ like those in this study. However, fishes from 3 localities, i.e., Wicheon (in Gunwi-gun, Gyeongsangbuk-do), Banbyeoncheon (in Yeongyang-gun, Gyeongsangbuk-do) and Yangcheon (in Sancheonggun, Gyeongsangnam-do), of Nakdonggang were highly and heavily infected with CsMc $[12,16]$.

Some species of freshwater fish edible in raw practically act as the infection source of clonorchiasis in Korea. Among 22 fish species examined in this study, 5 ones, i.e., crusian carp ( $C$. auratus), Korean and Japanese aucha perch (C. herzi and $C$. kawamebari), sweet smelt (Plecoglossus altivelis), and Korean dark sleeper (O. platycephala), are frequently eaten in raw in Korea. A total of 472 (28.6\%) fish edible in raw, i.e., 178 crusian carp, 19 Korean and 109 Japanese aucha perch, 92 sweet smelt and 74 Korean dark sleeper, were examined in this study, but only $2(0.4 \%)$ fish, 1 C. herzi and $1 \mathrm{O}$. platycephala, were infected with only 1 CsMc of each. In even such a highly endemic area, Wicheon, total 3 (8.8\%) out of 34 C. auratus were infected with total 3 CsMc, 2 (11.1\%) C. herzi were retained with 4 CsMc and only 1 (33.3\%) S. scherzeri were infected with total 6 CsMc, respectively [16]. No CsMc were detected in 4 fish species, i.e., C. herzi (57), C. auratus (42), S. scherzeri (11), and C. carpio (2), from Seomjin-gang [15]. Fortunately, these fish species edible in raw are less prevalent with CsMc in Korea. Then, what kinds of factors are acted in maintenance of the endemicity of clonorchiasis in Korea? The chopping board contaminated with fish meat may be act as the other transmission route of clonorchiasis in the riverside endemic areas of Korea.

Conclusively, it is confirmed that the endemicity of CsMc is moderately high in fishes from Tamjin-gang, which is known to be the endemic area of heterophyid flukes, including Metagonimus yokogawai and Heterophyes nocens [2,18-22]. The surveillances on the zoonotic fish-borne trematode infections should be constantly done in this river basin.

\section{ACKNOWLEDGMENTS}

This study was supported by an anti-communicable diseases control program, 2014E5400200 (Investigation of fish-borne parasites and acquisition of their biological resources in the southern regions of Korea) of National Institute of Health $(\mathrm{NIH})$, Korea Centers for Disease Control and Prevention (KCDCP). We thank Jung-A Kim and Hee-Joo Kim (Department of Parasitology and Tropical Medicine, Gyeongsang National University College of Medicine, Jinju, Korea), for their 
help in the examination of fish.

\section{CONFLICT OF INTEREST}

The authors have no conflicts of interest concerning the work reported in this paper.

\section{REFERENCES}

1. Korea Centers for Disease Control and Prevention. Korea National Institute of Health. National survey of the prevalence of intestinal parasitic infections in Korea, 2012. The 8th Report. Osong Chungcheongbuk-do, Korea. 2013.

2. Seo BS, Lee SH, Cho SY, Chai JY, Hong ST, Han IS, Sohn JS, Cho BH, Ahn SR, Lee SK, Chung SC, Kang KS, Shim HS, Hwang IS. An epidemiologic study on clonorchiasis and metagonimiasis in riverside areas in Korea. Korean J Parasitol 1981; 19: 137-150.

3. Rim HJ. The current pathobiology and chemotherapy of clonorchiasis. Korean J Parasitol 1986; 24 (suppl): 1-141.

4. Hong ST, Hong SJ. Clonorchis sinensis and clonorchiasis in Korea. Food-Borne Helminthiasis in Asia. Asian Parasitology 2005; 1: 35-56.

5. Cho SH, Lee KY, Lee BC, Cho PY, Cheun HI, Hong ST, Sohn WM, Kim TS. Prevalence of clonorchiasis in southern endemic areas of Korea in 2006. Korean J Parasitol 2008; 46: 133-137.

6. Jeong YI, Shin HE, Lee SE, Cheun HI, Ju JW, Kim JY, Park MY, Cho SH. Prevalence of Clonorchis sinensis infection among residents along 5 major rivers in the Republic of Korea. Korean J Parasitol 2016; 54: 215-219.

7. Sohn WM, Choi YS. Infection status with trematode metacercariae in the fresh-water fish from Chunamchosuchi (pond), Uichang-gun, Kyongsangnam-do, Korea. Korean J Parasitol 1997; 35: 165-170 (in Korea).

8. Kong HH, Choi BR, Moon HC, Choi DW. Larval digenetic trematodes from freshwater fish in river Miryang, Korea. Jpn J Parasitol 1995; 44: 112-1184.

9. Joo JY, Chung MS, Kim SJ, Kang CM. Changing patterns of Clonorchis sinensis infections in Kyongbuk, Korea. Korean J Parasitol 1997; 35: 155-164.

10. Kim EM, Kim JL, Choi SY, Kim JW, Kim S, Choi MH, Bae YM, Lee SH, Hong ST. Infection status of freshwater fish with metacercariae of Clonorchis sinensis in Korea. Korean J Paraitol 2008; 46: 247-251.

11. Sohn WM. Fish-borne zoonotic trematode metacercariae in the
Republic of Korea. Korean J Parasitol 2009; 47 (suppl): 103-113.

12. Cho SH, Sohn WM, Na BK, Kim TS, Kong Y, Eom K, Seok WS, Lee T. Prevalence of Clonorchis sinensis metacercariae in freshwater fish from three latitudinal regions of the Korean Peninsula. Korean J Parasitol 2011; 49: 385-398.

13. Cho SH, Lee WJ, Kim TS, Seok WS, Lee TJ, Jeong KJ, Na BK, Sohn WM. Prevalence of zoonotic trematode metacercariae in freshwater fish from Gangwon-do, Korea. Korean J Parasitol 2014; 52: 399-412.

14. Sohn WM, Na BK, Cho SH, Lee SW, Choi SB, Seok WS. Trematode metacercariae in freshwater fish from water systems of Hantangang and Imjingang in Republic of Korea. Korean J Parasitol 2015; 53: 289-298.

15. Sohn WM, Na BK, Cho SH, Park MY, Kim CH, Hwang MA, No KW, Yoon KB, Lim HC. Prevalence of Clonorchis sinensis metacercariae in fish from water systems of Seomjin-gang (River). Korean J Parasitol 2017; 55: 305-312.

16. Sohn WM, Na BK, Cho SH, Ju JW, Son DC. Prevalence and intensity of Clonorchis sinensis metacercariae in freshwater fish from Wicheon stream in Gunwi-gun, Gyeongsangbuk-do, Korea. Korean J Parasitol 2018; 56: 1-8.

17. Tamjingang in Jeonnam Province (South Korea) in Wikipedia The free encyclopedia: http://en.wikipedia.org.

18. Chai JY, Cho SY, Seo BS. Study on Metagonimus yokogawai (Katsurada, 1912) in Korea. IV. An epidemiological investigation along Tamjin river basin, South Cholla Do, Korea. Korean J Parasitol 1977; 15: 115-120.

19. Cho SH, Kim TS, Na BK, Sohn WM. Prevalence of Metagonimus metacercariae in sweetfish, Plecoglossus altivelis, from eastern and southern coastal areas in Korea. Korean J Parasitol 2011; 49: 161165.

20. Chai JY, Park JH, Han ET, Shin EH, Kim JL, Guk SM, Hong KS, Lee SH, Rim HJ. Prevalence of Heterophyes nocens and Pygidiopsis summa infections among residents of the western and southern coastal islands of the Republic of Korea. Am J Trop Med Hyg 2004; 71: 617-622.

21. Guk SM, Shin EH, Kim JL, Sohn WM, Hong KS, Yoon CH, Lee $\mathrm{SH}, \mathrm{Rim} \mathrm{HJ}$, Chai JY. A survey of Heterophyes nocens and Pygidiopsis summa metacercariae in mullets and gobies along the coastal areas of the Republic of Korea. Korean J Parasitol 2007; 45: 205211.

22. Park JH, Kim JL, Shin EH, Guk SM, Park YK, Chai JY. A new endemic focus of Heterophyes nocens and other heterophyid infections in a coastal area of Gangjin-gun, Jeollanam-do. Korean J Parasitol 2007; 45: 33-38. 